\title{
O BUSHIDÔ COMO INSTRUMENTO DE DIVULGAÇÃO DA CULTURA JAPONESA NO OCIDENTE
}

Gabriel Pinto Nunes ${ }^{1}$

Resumo: Este artigo foca o uso instrumental do bushidô por Inazô Nitobe durante a Era Meiji (18681912), em especial durante a Restauração Meiji, processo pelo qual houve profundas mudanças no cenário político, econômico e social do Japão, por meio da obra Bushido - The Soul of Japan, usada para divulgar a cultura japonesa às nações ocidentais com o intuito de aproximar e melhorar as relações entre o Japão e estas nações. De forma sucinta serão apontados os efeitos e usos, positivos e negativos, desta obra de Nitobe no ocidente nos anos que se seguiram a sua publicação.

Palavras-chave: Bushidô, Nitobe, Japão, Meiji, Ocidente.

Abstract: This article will focus on instrumental use of bushidô by Inazô Nitobe during the Meiji Era (1868-1912), especially during the Meiji Restoration, process whereby there were deep changes in the political scene, economic and social development of Japan, through the work Bushido - The Soul of Japan, used to disseminate the Japanese culture to Western nations to bring and improve relations between Japan and these nations. There will be a brief notes on the effects and uses, positive and negative, this work of Nitobe in the West in the years following its publication.

Keywords: Bushidô, Nitobe, Japan, Meiji, West.

\section{Introdução}

Não bastando o isolamento geográfico do Japão, por ser um país insular, o xogunato impôs uma política isolacionista (sakoku) por mais de duzentos anos que impediu o contato com a maioria das nações estrangeiras, em especial as europeias.

1. Mestrando em Língua, Literatura e Cultura Japonesa pela FFLCH-USP, bolsista pela Capes. 
Somente após a chegada do comandante Matthew Perry em 1853 houve a abertura dos portos japoneses às nações estrangeiras e em 1854 através do Tratado de Kanagawa ocorreu gradualmente a abertura econômica japonesa, a qual culminou com a Restauração Meiji. (JANSEN, 2000)

A abertura dos portos às nações estrangeiras provocou sérias mudanças políticas, econômicas e sociais no Japão, das quais podemos destacar a volta do poder político às mãos do Imperador após, como mencionado, mais de duzentos anos de governo xogunato, a criação de uma nova base governamental constitucional, parlamentarista e democrática, abolição do feudalismo e adoção do capitalismo liberal, divulgação e fortalecimento da ciência ocidental. (NITOBE, 1972b, p. 516)

Durante a Era Meiji (1868-1912) diversas foram as ações tomadas pelo governo japonês para tornar o país uma potência econômica mundial. Dentre as quais podemos destacar a aproximação comercial e cultural com as potências econômicas da época, como Estados Unidos, França e Reino Unido, assimilação da ciência ocidental para modernização da indústria e revigoramento de costumes antigos japoneses, com o intuito de criar uma identidade nacional que trouxesse a unificação de todos os povos do arquipélago, similar aos realizados por nações europeias ao longo de todo o século XIX e $\mathrm{XX}^{2}$. Para a concretização deste último, o xintoísmo se tornou a religião estatal e o neoconfucionismo foi adotado como doutrina do estado, estando presente tanto na Constituição Meiji de 1889 como no Édito Imperial de Educação de 1890, as quais difundiram e validaram a nova postura do governo japonês.

O bushidô, um sistema ético pertencente à classe dos samurais que teve seu ápice durante os primeiros anos da Era Tokugawa (1603-1868), sofreu diversas releituras até ser utilizado pelo governo como base moral de todo o povo japonês.

In the realm if thought, the bakufu, and most domains in imitation of it, embraced the Neo-Confucian doctrines Fo Chu Hsi, which stressed the moral basis of political authority and the need for absolute loyalty. The more theoretical and removed from the realities of the time the inherited warrior code became, the more rigidly the samurai adhered to it, developing an idealized combination of Confucianism and feudal ethics which came to be known as bushido, or "the way of the warrior." (REISCHAUER, 1987, p.102-103)

2. Segundo Hobsbawm (1997), estes processos de unificação territorial e de criação de uma identidade nacional ocorrida durante os séculos XIX e XX na Europa deram origem as nações modernas como as conhecemos. Tal processo era baseado em tradições, inventadas ou não, que remetiam a um passado comum aos povos para inculcar neles valores de patriotismo através da criação da identidade coletiva, unificando diversos povos sob uma mesma bandeira. 
O bushidô foi usado de duas maneiras distintas, uma esotérica ao povo japonês na qual o governo Meiji expandiu os valores de lealdade e honra do bushidô a todas as classes sociais, tendo apoio de uma parcela dos intelectuais da época, e uma exotérica sendo o conceito utilizado por Inazô Nitobe como instrumento de divulgação da Cultura Japonesa e aproximação do Japão do Ocidente. Bushido The Soul of Japan (1899) foi escrita em língua inglesa para o público ocidental e não para os japoneses, fato comprovado pelas diversas interpolações de autores e conceitos ocidentais ao longo de toda a obra, o que tornava a sua leitura difícil para os japoneses. Esta obra foi uma das primeiras responsáveis pela formação da imagem do japonês no imaginário ocidental moderno, facilitando reedições em diversos idiomas nos anos que se seguiram.

\section{Nitobe}

Inazô Nitobe nasceu em Morioka, atual prefeitura de Iwate, em 1 de setembro de 1862 (Bunkyû 2) em uma família de samurais que servia ao clã Nanbu. Faleceu aos 72 anos em Banff, Canadá, em 15 de outubro de 1933 (Shôwa 8) enquanto participava de uma Conferência do Instituto de Relações do Pacífico.

Aos 5 anos de idade perdeu o pai e passou a viver com o avô que o inseriu no mundo dos samurais. Anos mais tarde, devido ao falecimento do avô, muda-se desta vez para Tóquio para viver com o seu tio Ota, o qual dá continuidade aos estudos do sobrinho e o matricula em 1875 (Meiji 8) na Tokyo Eigo Gakkô Nesta escola, considerada na época preparatória para a Universidade Imperial de Tóquio, aprendeu inglês com Marion McCarrel Scott (1843-1922) que também o ensinou sobre o cristianismo.

A presença deste professor estadunidense em uma escola japonesa é consequência da política adotada pelo Governo Meiji para acelerar a modernização do Japão através da contratação de especialistas estrangeiros (oyatoi gaikokujin), os quais ministravam aulas e ajudavam a desenvolver a acanhada indústria japonesa, além do envio de japoneses ao exterior para estudarem e absorverem o máximo de conhecimento para depois transmiti-los aos seus conterrâneos.

Se não fosse pelo falecimento precoce de seu pai dificilmente Nitobe teria contato com a cultura estrangeira ainda em tenra idade. Tal incidente possibilitou uma familiaridade com a cultura ocidental, até então estranha e desconhecida no Japão. Seu interesse pelo ocidente na juventude pode ser ilustrado com a visita do Imperador Meiji a residência em Sanbongi de seu falecido avô no ano de 1876 (Meiji 9), na qual a família recebeu uma quantia em dinheiro como agradecimento pela acolhida do Imperador. (KITASAWA, 1953). Infelizmente, Nitobe não pode se encontrar com o Imperador na ocasião, pois estava em Tóquio estudando. Contudo, o dinheiro foi repartido entre os membros da família, ficando a Nitobe a menor 
parcela por ser o mais novo e por residir em Tóquio. Com o presente comprou uma Bíblia redigida em inglês e a usou para estudar com Marion Scott.

Seu interesse pelo ocidente continuou no ano seguinte quando entrou para a Faculdade Agrícola de Sapporo, na qual conheceu William Smith Clark (18261886) que assim como Scott estava no Japão para cumprir um contrato com o governo japonês. A figura de Clark foi a mais marcante influência ocidental direta para Nitobe. Além de fundar a Universidade de Hokkaidô, Clark foi responsável pela conversão de 31 jovens japoneses dentre os quais se encontrava Nitobe. Clark sempre dizia aos seus alunos: "Boys, be ambitious" (KITASAWA, 1953, p.10), inspirando-os a serem ambiciosos em suas conquistas pessoais.

Em seus estudos tornou-se um ávido leitor de livros em língua inglesa, o que fez ganhar dos amigos, o apelido de "monge" (KITASAWA, 1953). Isso contribuiu para que ele tivesse acesso às principais obras do mundo ocidental, sendo um dos poucos japoneses da sua época a possuir referências tão amplas e profundas sobre a cultura ocidental. Podia entender, como poucos de sua turma, os exemplos e explicações dadas pelos seus professores ocidentais, porém, tinha dificuldade na leitura de alguns kanjis, como escrito em carta a um amigo alguns anos mais tarde (NITOBE, 1939).

Outra grande influência em Nitobe, e consequentemente na sua obra, foi o escocês Thomas Carlyle (1795-1881) com a obra Sartor Resartus. Nitobe afirmava que por meio da leitura desta obra cheia de referências a cultura ocidental, encontrou forças para superar o falecimento de sua mãe em 1880 (Meiji 13). O estilo de Carlyle marcou Nitobe a tal ponto que seus comentadores (NAGAO, 2002 e HOWES, 1995) apontaram similaridades entre o estilo linguístico de ambos.

Passados alguns anos, em 1883 (Meiji 16), Nitobe entrou para a Universidade Imperial de Tóquio para cursar Economia, quando ocorreu um dos fatos mais conhecidos de sua vida, mencionado diversas vezes em seus escritos. Ao se matricular nas disciplinas de literatura inglesa o professor desta cátedra o questionou do motivo da escolha, já que era aluno de economia. Nitobe respondeu que queria ser a ponte que atravessava o Pacífico (NITOBE, 1972b), ou seja, queria ser um canal de comunicação entre o Japão e o ocidente, possibilitando a livre circulação de informações sem interferências.

Com o passar do tempo Nitobe percebeu que a Universidade Imperial de Tóquio não fornecia o conhecimento suficiente que ele almejava, enxergando nos Estados Unidos o destino para continuar seus estudos. Contando com a ajuda de seu tio, no ano de 1884 (Meiji 17) no seu aniversário de 24 anos, embarcou para os Estados Unidos para continuar seus estudos.

Nos Estados Unidos, Nitobe entrou para a Society of Friends, também conhecida como Quakers. Nitobe se tornou Quaker por influência de Roland Sletor Morris (1874-1945), conhecido por ser embaixador dos Estados Unidos no Japão 
durante a Primeira Guerra Mundial, inseriu-o nesta sociedade religiosa, na qual conheceu a sua Mary Patterson Elkinton, que se tornou sua esposa. A ideologia cristã seguida pelo grupo foi assimilada por Nitobe ao seu pensamento.

Ainda nos Estados Unidos Nitobe construiu uma extensa rede de amigos, os quais podem ser destacados: John Dewey (1859-1952), pensador pragmático e ilustre pedagogo, e Thomas Woodrow Wilson (1856-1924), futuro presidente dos Estados Unidos e quem concebeu a ideia de constituir a Liga das Nações a qual Nitobe foi representante do Japão de 1920 até 1926.

É indiscutível a influência dos novos pensamentos e da nova cultura que Nitobe assimilou nos anos em que passou no exterior. Antes de se casar com Mary Elkinton e retornar ao Japão ele passou três anos na Alemanha onde conseguiu o título de PhD na Universidade de Bonn.

\title{
3. Bushidô
}

O bushidô não é uma criação de Nitobe que apenas fez uma releitura de um conceito surgido por volta do Período Heian (794-1185), mas teve seu ápice no Período Edo (1603-1868). Em algumas famílias de samurais e clãs existia um código de condutas chamado de kakun, o qual apresentava algumas diferenciações de um grupo para outro, sendo secretos para uns, porém todos tinham em comum o fato de serem códigos de conduta os quais todos os samurais deveriam seguir. (NAVARRO, 2008, p.243).

Segundo Nitobe:

\begin{abstract}
Bushido, then, is the code of moral principles which the knights were required or instructed to observe. It is not a written code; at best it consists of a few maxims handed down from mouth to mouth or coming from the pen of some well-known warrior or savant. More frequently it is a code unuttered and unwritten, possessing all the more the powerful sanction of veritable deed, and of a law written on the fleshly tablets of the heart. It was founded not on the creation of one brain, however able, or on the life of a single personage, however renowned. It was an organic growth of decades and centuries of military career. (NITOBE, 1972a, p.25)
\end{abstract}

Furukawa (in MOORE, 1975, p. 228) ressalta que na obra Hakagure de Tsunemoto, escrito por volta de 1716, há referências explícitas ao bushidô: "Bushidô towa shinu koto to mitsuke tari" 3 Contudo, o Bushidô apresentado nesta obra é muito mais simples que o desenvolvido e apresentado ao ocidente por Nitobe.

O bushidô presente na obra Hakagure e na obra de Nitobe não devem ser confundidos com o Buke Shohatto, um Estatuto Militar promulgado pela primei-

3. Bushidô consiste em morrer. 
ra vez em 1615 que tratava de algumas regras a serem seguidas no Japão. Neste estatuto há referências à classe samurai, como a obrigação deles em se dedicar a ações que favorecessem a classe, como a arquearia, esgrima, hipismo e caligrafia, além de impor a simplicidade aos samurais (JANSEN, 2000). Tanto o Hakagure quanto o Buke Shohatto não delimitam a origem do bushidô, apenas indicam que este conceito já era corrente na época em que foram escritos e diferem da última versão do bushidô por serem como compêndios de normas a serem seguidas, não estabelecendo uma categoria de valores complexa.

Ota (in NAGAO, 2006, p. 242) enumera diversas aparições do termo bushidô anteriores à publicação da obra de Nitobe. Podemos destacar: Ishida Bunshirô - Nihon Bushidô Shin no Taikeiteki Kenkyû de Katô Kiyomasa (1562-1611), Bushidô de Daidôji Yûzan (1639-1730) e o seu discípulo Yamaga Sokô (1622-1685) que apresentava um conceito menos violento do bushidô, chamado por eles de shidô.

O Bushidô de Yûzan foi escrito em tempos de paz no Japão e por isso é possível notarmos na obra uma preocupação em ocupar o samurai com outras atividades que não fossem a guerra, como a necessidade de torná-los letrados, sendo o analfabeto inapropriado para se tornar um verdadeiro samurai. Tal obra é um grande manual de regras para a classe samurai, com exposição da forma e maneira que costumes do cotidiano deveriam ser seguidos, ou seja, uma preocupação com o kata.

Nitobe se preocupou, quando possível, em dar explicações sobre alguns costumes e valores da classe samurai, evitando citar apenas as regras de etiqueta, como fez Yûzan. A maior preocupação da obra de Yûzan é a busca pelo equilíbrio entre o militar (shi) e a cultura (bun) por meio do kata.

\section{O Bushidô de Nitobe}

Devemos ter em mente que uma das principais diferenças entre o bushidô nitobiano e os demais é que este nunca foi utilizado na prática, ou seja, foi compilado especificamente para ser apresentado aos ocidentais, enquanto que todos os outros tiveram em algum momento da história do Japão uma aplicação prática. Independente de terem ou não sido usados, todas as concepções de bushidô apresentam três influências em comum: o confucionismo, o xintoísmo e o budismo. $\mathrm{O}$ bushidô de Nitobe apresenta uma quarta influência particular: o cristianismo.

A primeira influência do bushidô de Nitobe, o confucionismo, teve como referências a Constituição Meiji de 1889 e o Édito Imperial da Educação de 1890. Esta doutrina filosófica de origem chinesa forneceu a estrutura ética básica do bushidô para que este pudesse se formalizar como código ético com ênfase nas virtudes, $g i$, a piedade filial, o compromisso moral, giri, a retidão e obediência ao superior. O compromisso do samurai em tirar a própria vida como prova de servidão ao daimyô é uma exteriorização de um forte sentimento de respeito e dedicação. 
A segunda influência é o xintoísmo, a primeira religião do povo japonês criada para dar uma identidade cultural comum ao povo japonês. Tem como base o Kojiki, livro entregue a Imperatriz Gemmei na qual há a teogonia das divindades japonesas, considerando os membros da Família Imperial Japonesa como descendentes diretos destas divindades e o povo japonês descendente de membros da Família Imperial. O nome shintô significa caminho dos deuses.

O xintoísmo sofreu um processo de assimilação com o confucionismo e com o budismo ao longo dos anos, o que tornou dificil dissociarmos o que realmente é xintoísmo e o que não é. Porém há dois valores que, segundo Nitobe, são essencialmente xintoístas: o patriotismo e a lealdade ${ }^{4}$. As demais doutrinas que se assimilaram vieram para dar sustento ao que é proposto pelo xintoísmo, através de sua teogonia que liga todos os japoneses através de um laço sanguíneo.

O budismo de origem indiana chegou ao Japão através da China e Coreia. Assim como o xintoísmo e o confucionismo, possui uma parte religiosa e outra filosófica que são indissociáveis. É considerada por Nitobe a fonte do estoicismo do samurai pelo seu desapego aos sentimentos e a materialidade do mundo, pois o budismo afirma a inexistência do eu, que a vida e o apego às coisas materiais acarretam em sofrimento. Afirma ser inútil se apegar a qualquer coisa visto que nada é perene e ter o conhecimento da morte traz sofrimento. Este estoicismo oriental garante ao guerreiro uma morte tranquila, sem preocupações mundanas que possam vir a interferir no cumprimento do dever e evita que o medo da morte dilua a coragem e bravura do samurai durante a batalha.

Estas três correntes consideradas indissociáveis dentro da cultura japonesa que deram respaldo ao bushidô por muitos anos (YUSA, 2002). Nitobe apenas fez algumas adições ao conceito, sendo o cristianismo a mais evidente aos olhos ocidentais. Ao tratar da retidão ou justiça no terceiro capítulo do Bushido, Nitobe cita Mencius que afirmava ser a integridade o caminho para o homem atingir o paraíso perdido, porém Nitobe o desdiz dizendo que o único e verdadeiro caminho é através de Jesus (NITOBE, 1972a, p.36). Tal interferência de Nitobe não é casual e possibilitou aos estrangeiros, neste caso os estadunidenses e europeus, assimilarem com maior facilidade o bushidô por encontrar pontos em comum entre as culturas.

\section{O bushidô como instrumento de divulgação}

O uso do bushidô foi expandido a toda a sociedade japonesa pelo governo Meiji como parte do processo de criação de unidade nacional em torno de ideais gerais. Nitobe buscou usar este código de valores como meio de aproximação com

4. No confucionismo também existia o valor da lealdade, mas na leitura de Nitobe a versão xintoísta foi privilegiada por haver comprometimento com a figura do Imperador e, consequentemente, uma lealdade ao novo estado que se constituía baseada na figura deste líder. 
as nações do ocidente, acreditava que conhecer um povo através da moral possibilitaria uma assimilação mais rápida dos valores e costumes japoneses tornando mais eficiente o processo de aproximação política e econômica.

Segundo Nitobe, no prefácio de Bushido - The Soul of Japan, a primeira motivação para escrever a obra foi devido à indagação do jurista belga Laveleye, que em um encontro com Nitobe questionou-o como os japoneses aprendiam sobre a moral.

\begin{abstract}
About then years ago, while spending a few days under the hospitable roof of the distinguished Belgian jurist, the lamented $\mathrm{M}$. de Laveleye, our conversation turned during one of our rambles, to the subject of religion. "Do you mean to say," asked the venerable professor, "that you have no religious instruction in your schools?" On my replying in the negative he suddenly halted in astonishment, and in a voice which I shall not easily forget, he repeated "No religion! How do you impart moral education?" The question stunned me at the time. I could give no ready answer, for the moral precepts I learned in my childhood days were not given in schools; and not until I began to analyze the different elements that formed my notions of right and wrong, did I find that it was Bushido that breathed them into my nostrils. (NITOBE, 1972a, p.7)
\end{abstract}

A segunda motivação surgiu de sua esposa, Mary Elkinton que queria entender alguns conceitos comuns aos japoneses. Da tentativa de resposta surgiu a obra.

The direct inception of this little book is due to the frequent queries put by my wife as to the reasons why such and such ideas and customs prevail in Japan.

In my attempts to give satisfactory replies to $M$. de Laveleye and to my wife, I found that without understanding feudalism and Bushido, the moral ideas of present Japan are a sealed volume. (NITOBE, 1972a, p.7)

Powels (1995) cita diversos autores que mencionam a obra de Nitobe e o impacto que representou no mundo ocidental. Por muitos anos foi a principal obra a apresentar formalmente aos ocidentais o Japão, visto como um compêndio de tudo aquilo que um estrangeiro deveria saber sobre a moral japonesa e muito usada pelos missionários protestantes que iam ao Japão para evangelizar.

Uma das maiores referências citadas por inúmeros autores é a prática do presidente estadunidense Roosevelt que, não só distribuía cópias do livro de Nitobe aos seus amigos para que estes conhecessem um pouco mais da cultura japonesa, como iniciou treinos de judô com um dos discípulos de Jigorô Kanô $\hat{~}^{5}$ para aprofundar-se no conhecimento da cultura japonesa. Tal feito foi mencionado pelo próprio Nitobe no prefácio da décima edição revisada do Bushido publicada em 1905.

5 Fundador da arte marcial conhecida como Judô. 
I have been more than gratified to feel that my humble work has found sympathetic readers in widely separated circles, showing that the subject matter is of some interest to the world at large. Exceedingly flattering is the news that has reached me from official sources, that President Roosevelt has done it undeserved honor by reading it and distributing several dozens of copies among his friends. (NITOBE, 1972a, p.11)

A obra logo se tornou conhecida em toda a Europa com traduções em diversos idiomas acompanhadas por Nitobe. Isso o orgulhava muito, pois entendia que a sua motivação em apresentar o Japão aos ocidentais estava ganhando dimensões que nem ele mesmo esperava. Um pouco antes no mesmo prefácio ele diz:

In the meantime, Bushido has been translated into Mahratti by Mr. Dev of Khanclesh, into German by Fraulcin Kaufmann of Hamburg, into Bohemian by Mr. Mora of Chicago, into Polish by the Society of Science and Life in Lemberg, although this Polish edition has been censured by the Russian Government. It is now being rendered into Norwegian and into French. A Chinese translation is under contemplation, A Russian officer, now a prisoner in Japan, has a manuscript in Russian ready for the press. A part of the volume has been brought before the Hungarian public and a detailed review, almost amounting to a commentary, has been published in Japanese. Full scholarly notes for the help of younger students have been compiled by my friend $\mathrm{Mr}$. $\mathrm{H}$. Sakurai, to whom I also owe much for his aid in other ways. (NITOBE, 1972a, p.11)

Sempre que possível Nitobe tentava redigir um prefácio especifico para cada nova edição, ressaltando a íntima relação que poderia existir entre a cultura da nação que recebia uma nova tradução do Bushido e a cultura nipônica. Esforçava-se para estabelecer vínculos com todos os povos, característica proveniente de seus valores como Quaker.

A people so intensely loyal to the memory of the past, so ardently attached to the land of their fathers, so gifted with manly virtues and possessed of so chequered a history, will find many points in common with us. (NITOBE, 1972a, p. 238)

Todavia, em alguns países, como a Espanha, a tradução do Bushido foi feita com a intenção de apoiar os regimes fascistas que se encontravam em ascensão. Navarro (2009) afirma que o general espanhol Milan-Austray fez uma tradução tendenciosa que era usada no treinamento militar da legião estrangeira espanhola.

Infelizmente a obra foi descontextualizada por regimes fascistas como referência para justificar o ufanismo. Servia de manual para ensinar os cadetes do exército a importância do patriotismo, mas de maneira chauvinista. Nitobe diferenciava o patriotismo do chauvisnismo, um patriota é um internacionalista, pois para que uma pessoa ame a sua nação é necessário que ame a nação do outro. Tal explicação é uma clara referência à passagem bíblica de Mateus 22,39 (Amai o próximo como a ti mesmo). 
The antithesis of patriotism is not internationalism or cosmopolitanism, but Chauvinism. If you love your country, you must needs love other countries without which your own country cannot exist and loses its raison d'être. If you love the world, you must, perforce, love best that part of it which is nearest to you. (NITOBE, 1972c, p.35)

Para ele o chauvinista é aquele que diz amar ou exaltar a própria pátria de modo errôneo por impor a superioridade de seu pensamento e valores sobre os demais. É aquele que nega a cultura do outro e somente aceita a coexistência com o estrangeiro se este aceitar ser subjugado e, para Nitobe, quando se nega o outro nega a si mesmo.

Os ataques à obra também tiveram destaque com Basil Hall Chamberlain, outro oyatoi gaikokujin que o acusava de inventar o termo bushidô. Afirmava que tal palavra nunca apareceu na historiografia japonesa, como exposto em The Invention of a New Religion:

As for Bushido, so modern a thing is it that neither Kaempfer, Siebold, Satow, nor Rein--all men knowing their Japan by heart --ever once allude to it in their voluminous writings. The cause of their silence is not far to seek: Bushido was unknown until a decade or two ago! THE VERY WORD APPEARS IN NO DICTIONARY, NATIVE OR FOREIGN, BEFORE THE YEAR 1900. Chivalrous individuals of course existed in Japan, as in all countries at every period; but Bushido, as an institution or a code of rules, has never existed. The accounts given of it have been fabricated out of whole cloth, chiefly for foreign consumption. An analysis of medieval Japanese history shows that the great feudal houses, so far from displaying an excessive idealism in the matter of fealty to one emperor, one lord, or one party, had evolved the eminently practical plan of letting their different members take different sides, so that the family as a whole might come out as winner in any event, and thus avoid the confiscation of its lands. Cases, no doubt, occurred of devotion to losing causes--for example, to Mikados in disgrace; but they were less common than in the more romantic West. (CHAMBERLAIN, 1900)

A postura de Chamberlain é facilmente refutável, como já mencionado por Ota (in NAGAO, 2006, p. 242) houve várias versões e referências ao bushidô antes da obra de Nitobe. Chamberlain ignora o uso de alguns sinônimos como bushi-no-michi. (POWELS, 1995, p.114)

\section{Conclusão}

Para entendermos os objetivos de Nitobe ao difundir a cultura japonesa através do bushidô primeiramente temos que ter em mente o processo de rápidas mudanças políticas, econômicas, sociais e culturais ocorridas no Japão iniciadas com a Restauração Meiji e que tornaram o país em uma potência econômica em 
poucos anos. Até a capital foi renomeada com o intuito de mostrar que ali nascia um país com novos horizontes.

O bushidô dá respaldo à legitimidade ao Imperador e ao sistema cultural e religioso escolhido para ser a nova tradição do japonês moderno. Como dito por Hobsbawm em A Invenção das Tradições:

\begin{abstract}
A "tradição" neste sentido deve ser nitidamente diferenciada do "costume" vigente nas sociedades ditas "tradicionais". O objetivo e a característica das "tradições" inclusive das inventadas, é a invariabilidade. O passado real ou forjado a que elas se referem impõe práticas fixas (normalmente formalizadas), tais como a repetição. $\mathrm{O}$ "costume", nas sociedades tradicionais, tem a dupla função de motor e volante. Não impede as inovações e pode mudar até certo ponto, embora evidentemente seja tolhido pela exigência de que deve parecer compatível ou idêntico ao precedente. Sua função é dar a qualquer mudança desejada (ou resistência à inovação) a sanção do precedente, continuidade histórica e direitos naturais conforme o expresso na história. (HOBSBAWM, 1997, p. 10)
\end{abstract}

O proposto por Nitobe estava em concordância com os objetivos do Governo Meiji, utilizou-se de uma nova tradição baseada em um antigo sistema de valores que continha um misto de passado real e forjado, mas que permitia ao Japão a sua modernização para torná-lo uma potência econômica, além de fornecer uma imagem de continuidade natural ao proposto pelo xintoísmo e outros cultos que afirmavam existir um laço sanguíneo e familiar do povo japonês com a descendência divina da Família Imperial.

\begin{abstract}
Porém, o imperador era uma figura nominal e o verdadeiro poder do novo governo Meiji estava nas mãos da hierarquia superior dos seus oficiais, constituída pelos cortesãos nobres e samurais de mérito que haviam tomado o partido da corte imperial e que, com êxito, tinham feito a transição do poder do xogum para o imperador. Desde o princípio que o novo governo quis agradar a gregos e troianos. Ao ocidente, quando adoptou políticas que progressivamente "encorajavam a indústria, fortaleciam a economia e criavam um exército forte". Mas quis também seguir as antigas raízes religiosas e culturais, que protegiam interesses nacionalistas e conservadores. Estas duas direcções contraditórias - a criação de um Estado-nação moderno, industrializado e capitalista, ao mesmo tempo que regressava às antigas raízes do país - acabaram por se juntar no xintoísmo de Estado (Kokka Shinto), o sistema de santuários xintoístas protegidos pelo Estado. (YUSA, 2002, p. 97)
\end{abstract}

Nitobe aproveitou o pensamento da época e constituiu o seu bushidô. Até mesmo a interferência cristã foi benéfica para facilitar a aceitação pelas nações ocidentais que tinham no cristianismo suas principais fontes de valores éticos. Essa visão de Nitobe foi corroborada pela missão diplomática japonesa conhecida como "Missão Iwakura" enviada a Europa e Estados Unidos em 1871 que averiguou 
ser a perseguição aos cristãos no Japão nocivo às relações diplomáticas (YUSA, 2002, p. 100).

O uso do bushidô como instrumento de divulgação da cultura japonesa teve uma excelente aceitação ao redor do mundo, sendo associado no pensamento contemporâneo ocidental o samurai como figura representativa do japonês (DAVIES, 2002). Até mesmo a descaracterização do conceito usado pelos fascistas é prova da enorme divulgação e interesse que o bushidô despertou no público ocidental.

Sem dúvida Nitobe foi um homem de seu tempo, ao compreender perfeitamente o que acontecia ao seu redor e pela sua atuação ativa nos mais diversos campos do saber. Continua sendo um exemplo a ser seguido pelas futuras gerações, estando no Bushido uma importante parte do seu legado.

\section{Bibliografia}

BENEDICT, Ruth. O Crisântemo e a Espada. São Paulo: Perspectiva, 2007

CHAMBERLAIN, Basil Hall. The Invention of a New Religion, 1900.

CORDARO, Madalena Natsuko Hashimoto. O Pensamento no Período Edo (1603-1868). In: Estudos Japoneses, n.18, p. 77-100, São Paulo: CEJAP-USP, 1998

DAVIES, Roger J. IKENO, Osamu. The Japanese Mind, Understanding Contemporary Japanese Culture. Tóquio: Tuttle Publishing Tokyo, 2002.

HOBSBAWM, Eric. A Invenção das Tradições. São Paulo: Paz e Terra, 1997.

HOLTOM, Daniel Clarence. Un Estudio sobre el Shintô Moderno - La Fe Nacional del Japón. Barcelona: Paidós Orientalia, 2004.

HOWES, John F. Nitobe Inazô - Japan's Brigde Across the Pacific. São Francisco: Westview Press, 1995.

JANSEN, Marius Berthus. The Making of Modern Japan. Cambridge: Harvard University Press, 2000.

KITASAWA, Sukeo. The Life of Dr. Nitobe. Tóquio: Hokuseido Press, 1953.

MOORE. Charles A. The Japanese Mind - Essentials of Japanese Philosophy and Culture. Honolulu: University Press of Hawaii, 1975.

NAGAO, Teruhiko. Nitobe Inazô from Bushido to the League of Nations. Tóquio: Hokkaido University Press, 2006.

NAVARRO, Maria Teresa Rodríguez. Análisis de la Obra: Bushido, The Soul of Japan de Inazô Nitobe, desde la Triple Perspective Traductológica, Cultural y Jurídica. Tese de doutorado. Granada: Universidade de Granada, 2007.

El Discurso Orientalista en la Traducción Francesa (1927) del Bushido de Nitobe. Inter Asia Papers, Barcelona, n. 5, p. 1-26, 2008. 
. MUÑOZ, Rafael Serrano. La Influencia del Bushidô en La Constitución Japonesa de 1889 y en El Edicto Imperial de La Educación de 1890. Nuevas Perspectivas de Investigación sobre Asia Pacifico, Granada: Editorial Universidad de Granada, n. 2, p.239-253, 2008. . BEEBY, Allison. Millán-Astray's Translation of Nitobe's Bushido: The Soul of Japan. Translator's Journal, Montréal: Universidade de Montreal, vol. 54, nº 2, 2009, p.218-232.

NITOBE, Inazô. Letters to Dr. Kingo Miyabe (1884-1889) (Nitobe Inazô no Tegami). Tóquio, 1939.

The Works of Inazo Nitobe. Vol. I, Tóquio: University Of Tokyo Press, 1972a.

The Works of Inazo Nitobe. Vol. IV, Tóquio: University Of Tokyo Press, 1972b.

The Works of Inazo Nitobe. Vol. V, Tóquio: University Of Tokyo Press, 1972c.

TSUNETOMO, Yamamoto. Hagakure - Book of the Samurai. 2005.

YUSA, Michiko. Religiões do Japão. Lisboa: Edições 70, 2002.

YUZAN, Daidoji. Bushidô - O Código do Samurai. São Paulo: Madras, 2004. 